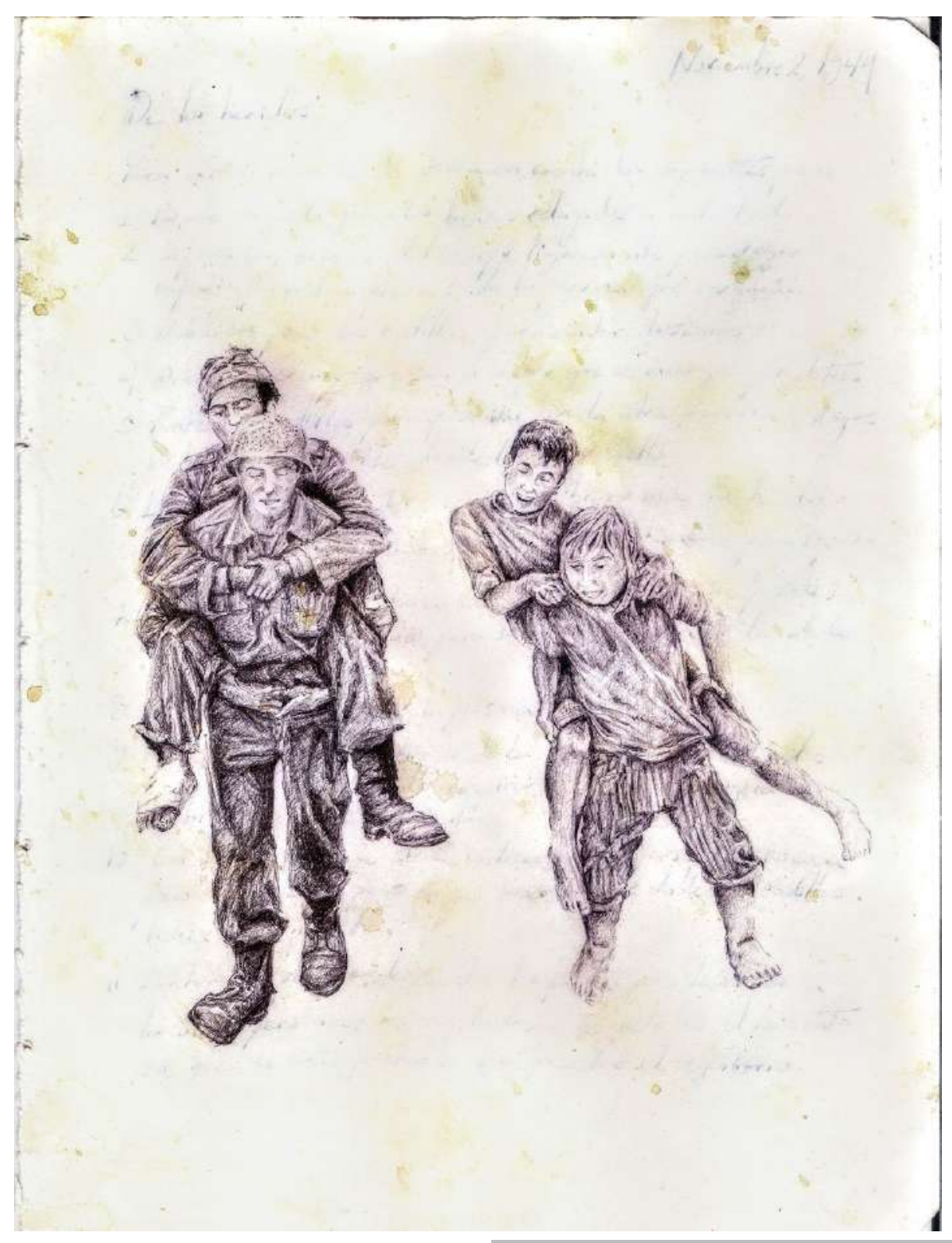

Sebastián Zea Quintero

Sin título

De la serie Del juego y el hombre Lápiz sobre papel

2017

Medellín 


\title{
Sociabilidad política y grupos políticos. El radicalismo universitario en la Ciudad de Santa Fe, 2007-2015*
}

\author{
Matías Landau**
}

\section{Resumen}

Los estudios de sociología política que analizan las dinámicas políticopartidarias se concentran con frecuencia en una escala nacional o provincial. Son más escasos los trabajos sobre la relación entre sociabilidades, espacios partidarios y formas de despliegue del trabajo político en el ámbito local. Este artículo apunta a contribuir en esa dirección, a partir de una investigación desarrollada en la ciudad argentina de Santa Fe. El enfoque propuesto identifica al grupo como la unidad de análisis que permite dar cuenta de la relación entre sociabilidad y política en el ámbito local. El análisis se enfoca en un grupo político conocido localmente como los «radicales universitarios» o el «grupo universidad». El objetivo es analizar el modo en que las relaciones interpersonales y los vínculos de lealtad y solidaridad entre individuos con pertenencias y tránsitos institucionales distintos construyeron un grupo político con participación en diversos espacios institucionales -militancia estudiantil, gestión universitaria, partido político, administración municipal-. Se señalan diversos factores en la consolidación de un grupo político: las identidades políticas, las generaciones, las movilizaciones, las instituciones, las redes y los liderazgos.

\section{Palabras clave}

Partidos Políticos; Política Local; Grupos Políticos; Sociabilidad Política; Argentina.

Fecha de recepción: octubre de 2019 - Fecha de aprobación: mayo de 2020

\footnotetext{
* Este artículo se deriva la investigación realizada en el marco del proyecto CAI+D 2011, Elites políticas y gobierno en la Ciudad de Santa Fe (código 50120110100424 LI), con sede en la Facultad de Humanidades y Ciencias, Universidad Nacional del Litoral, Argentina. Proyecto dirigido por Matías Landau y en el cual participaron profesores, graduados y alumnos avanzados de la carrera de Sociología. Los datos empíricos que sustentan este artículo son fruto del esfuerzo colectivo llevado a cabo por todos ellos.

** Licenciado en Sociología. Magíster en Investigación en Ciencias Sociales. Doctor en Sociología y doctor en Ciencias Sociales. Investigador del Consejo Nacional de Investigaciones Científicas y Técnicas (Conicet) en el Instituto de Investigaciones Gino Germani, Universidad de Buenos Aires, Argentina. Correo: malandau@sociales.uba.ar
} 


\title{
Cómo citar este artículo
}

Landau, Matías. (2020). Sociabilidad política y grupos políticos. El radicalismo universitario en la Ciudad de Santa Fe, 2007-2015. Estudios Políticos (Universidad de Antioquia), 58. pp. 263-284. DOI: 10.17533/udea.espo.n58a12

\section{Political Sociability and Political Groups. University Radicalism in the City of Santa Fe, 2007-2015}

\begin{abstract}
Political sociology studies that analyze party-political dynamics often focus on a national or provincial scale. There are fewer works on the relationship between sociabilities, partisan spaces, and political work at the local level. This article aims to contribute in this direction, based on research carried out in the Argentine city of Santa Fe. The study focuses on a political group known locally as the «university radicals» or the "university group», which is identified as the unit of analysis that allows us to account for the relationship between sociability and politics at the local level. The objective is to show how interpersonal relationships, loyalty, and solidarity ties between individuals with different institutional affiliations and transits built a political group with participation in various institutional spaces (student

[264] militancy, university management, political party, municipal administration). We point out various factors in the consolidation of a political group: political identities, generations, mobilizations, institutions, networks, and leaders.
\end{abstract}

\section{Keywords} Argentina.

Political Parties; Local Politics; Political Groups; Political Sociability; 
Sociabilidad política y grupos políticos. El radicalismo universitario en la Ciudad de Santa Fe...

\section{Introducción}

En América Latina en general y en Argentina en particular gran parte de los trabajos de sociología política que se concentran en la escala local se reducen a un análisis del tipo de vínculo que se entabla entre autoridades políticas y habitantes bajo las dinámicas de clientelismo (Auyero, 2001) o de diversas formas de participación ciudadana (Annunziata, 2016; Landau, 2008). Son menos frecuentes los estudios que indagan en la relación entre sociabilidades, partidos políticos, espacios institucionales y formas de militancia.

Sin embargo, como han demostrado diversos estudios (Dahl, 1961; Briquet y Sawicki, 1989; Gaxie, 1994), la escala municipal es clave para el estudio de la política. Como han sugerido Jean-Louis Briquet y Frederic Sawicki (1989, pp. 11-12), el espacio político local es un lugar de memoria y de formación de identidades, y de prácticas políticas específicas, ya que la historia, presente en el espacio y en las instituciones, se inscribe en los cuerpos de quienes las habitan. Hay, por tanto, una relación estrecha entre las formas específicas de la sociabilidad local y la configuración de la actividad política.

A partir de estos presupuestos, este artículo apunta a contribuir en el estudio de la sociabilidad política en el ámbito municipal, basados en datos construidos a partir una investigación desarrollada en la ciudad argentina de Santa Fe, una ciudad intermedia, capital provincial, con una rica historia local nutrida por las principales identidades políticas argentinas, como el radicalismo y el peronismo (Aboy Carlés, 2001), y que cuenta con una amplia red institucional en la que se despliegan prácticas de militancia en los ámbitos universitario, partidario y barrial. Todo ello la constituye en un interesante laboratorio de análisis.

La ciudad de Santa Fe está situada en el centro del país y es Capital de la provincia homónima. Tiene una población de aproximadamente 300 000 habitantes, la cual asciende a medio millón si se suman los habitantes del área metropolitana. La cercanía con la ciudad de Paraná, Capital de la provincia de Entre Ríos, de la que está unida por un túnel subfluvial que atraviesa el río Paraná, constituye un polo conjunto de 850000 habitantes, aproximadamente. Se encuentra en una zona propicia para las actividades 
agropecuarias que se desarrollan en zonas rurales y pequeños pueblos cercanos. Como capital provincial es un centro administrativo que concentra instituciones provinciales y municipales. También es la sede de la Universidad Nacional del Litoral (UNL), creada en 1919, de prestigio nacional y que atrae a estudiantes tanto de la misma ciudad como de zonas aledañas.

El enfoque aquí propuesto identifica al grupo como la unidad de análisis que permite dar cuenta de la relación entre sociabilidad y política en el ámbito local. Se entiende la sociabilidad, tal como ha sido abordada por diversos estudios históricos y sociológicos, como prácticas sociales que crean vínculos y agrupan a los individuos que forman parte de ellas (Agulhon, 2009; González, 2001; 2008; Losada, 2008; Beccaria et al., 2002). En este sentido, dicho concepto se asocia naturalmente al de grupo, en tanto modalidad que adquiere este lazo recíproco. Los estudios sobre las formas de sociabilidad han señalado la importancia de compartir ciertos espacios institucionales, como clubes, asociaciones o partidos (Agulhon, 2009); pero también han señalado que los vínculos creados exceden lo institucional o, en términos simmelianos, se constituyen en un estado lúdico del proceso de socialización, por el mero gusto de estar juntos (Simmel, 2002). En este sentido, la sociabilidad contribuye a generar un espacio de reconocimiento mutuo, un nosotros, por parte de quienes forman el grupo, al mismo tiempo que se crean las fronteras que los separan de los demás (Gurvitch, 1938).

La actividad política, como cualquier otra actividad social, está permeada por formas de sociabilidad que permiten que individuos compartan ciertos espacios institucionales, prácticas y representaciones a partir de los cuales se ven atraídos. El resultado, cuando el vínculo es duradero, es la conformación de un grupo político, entendido como individuos que se reconocen como parte de un mismo colectivo, unido en la búsqueda por ganar cargos decisorios a partir de las disputas de espacios de poder, frecuentemente, a partir de elecciones en diversas instituciones como partidos políticos, universidades, sindicatos, entre otros.

Dentro de los estudios de sociología política, los grupos son estudiados con frecuencia en tanto grupos de interés, es decir, formas de construcción de lazos entre individuos que tienen como objetivo común posicionar algún tema en la agenda pública y, eventualmente, influir en las autoridades (Solís, 2017). Son más escasos los estudios sobre grupos políticos, esto se debe, 
en muchos casos, a la primacía que adquiere la dimensión institucional — en mayor medida, dada por el estudio del partido político como unidad de análisis- por sobre la grupal. En ese caso, los grupos son considerados como «facciones» o «líneas» partidarias y leídos en función de las pujas internas propias de las dinámicas organizacionales partisanas (Espejel, 2013). Si bien esta mirada clásica es central para comprender el funcionamiento de los partidos políticos, no permite dar cuenta de procesos en los que el partido es solo uno de los espacios institucionales de los grupos políticos.

Algunos estudios que renovaron el campo de la investigación sobre partidos políticos se han preocupado por analizar el «entorno partidista» (Sawicki, 2011), es decir, las redes de sociabilidad más o menos formales donde el partido político encuentra un medio propicio para desarrollarse y reclutar a sus miembros. En complementariedad con este enfoque, se propone un análisis que no comienza desde el partido, sino que se enfoca en el modo en que se tejen lazos sociales en forma de grupo, el cual permite actuar en distintos espacios institucionales a la vez, que incluyen, pero exceden el partidario. A la manera de una intersección de conjuntos, es posible analizar cómo un núcleo grupal tiene más desarrollada su multiposicionalidad (Boltanski, 1973), mientras que otros miembros del grupo participan de algunos de estos espacios, pero no de otros.

El caso santafesino aporta una experiencia reciente que permite comprender este tipo de lazo. Se trata del grupo conocido como los «radicales universitarios» o el «grupo universidad». El objetivo del artículo es analizar el modo en que las relaciones interpersonales, los vínculos de lealtad y solidaridad entre individuos con pertenencias y tránsitos institucionales distintos construyeron un grupo político y les permitieron disputar espacios decisorios en diversas instituciones. En este sentido, el análisis institucional (Lagroye y Offerlé, 2010) se complementa con el grupal.

En cuanto a la metodología utilizada, se contempla el análisis prosopográfico de un conjunto de individuos y el estudio de su trayectorias, prácticas y formas de construcción de vínculos cotidianos. Los datos empíricos son resultado de una investigación realizada en el marco del proyecto Elites políticas y gobierno en la Ciudad de Santa Fe con sede en la Facultad de Humanidades y Ciencias, Universidad Nacional del Litoral, Argentina. Entre 2016 y 2018, se realizaron veintitrés entrevistas semiestructuradas a todos los 
individuos de ese grupo que hayan ocupado cargos de intendente, secretario municipal o concejal en el periodo 2007-2015 en la Ciudad de Santa Fe. Gracias a la buena predisposición de todos ellos se logró acceder a la totalidad del universo en cuestión, que abarca la gestión de Mario Barletta (2007-2011) y la primera gestión de José Corral (2011-2015). Se trata de quince individuos que ocuparon un cargo de secretario municipal, cuatro que fueron concejales, dos que fueron concejales y secretarios municipales, uno que fue concejal, secretario e intendente, y uno que fue solo intendente.

El análisis propuesto articula los métodos propios de los análisis biográficos (Sautú, 1999; Meccia, 2019) y de trayectorias (Passeron, 1990; Dubar, 1998). Para ello se recuperó la palabra de los entrevistados y se reconstruyó, a partir de sus experiencias narradas, una historia personal y colectiva. Como ocurre con toda investigación cualitativa basada en entrevistas, hay un sesgo ineludible respecto a la lectura que los actores realizan sobre sus acciones pasadas denominado «ilusión biográfica» (Bourdieu, 1986). Para afrontar esta limitación, la multiplicación de las voces, en este caso de los distintos actores entrevistados, pero también de otros informantes clave, enriquece la reconstrucción histórica. En este caso, hemos entrevistado a quince concejales o dirigentes políticos santafesinos no pertenecientes al grupo estudiado, quienes permitieron observar el fenómeno desde otra perspectiva y corroborar ciertas afirmaciones o recuerdos de los entrevistados. Asimismo, se chequearon ciertos datos públicos con medios de prensa, aun cuando el objetivo primordial es la reconstrucción del sentido dado por parte de los actores estudiados.

\section{La militancia universitaria}

Diversos estudios han demostrado el rol que desempeñan algunos contextos específicos proclives a favorecer el involucramiento y compromiso colectivo (Ihl, 2002). En la década de 1980, luego de la recuperación democrática en Argentina tras la dictadura entre 1976 y 1983, se vivía lo que para muchos jóvenes simpatizantes de la Unión Cívica Radical (UCR) fue la «primavera alfonsinista». En esos primeros años posteriores a los oscuros del terrorismo de Estado, la militancia floreció y los colegios secundarios y las universidades se convirtieron en un espacio de participación política privilegiado (Vázquez, Vommaro, Nuñez y Blanco, 2017). En Santa Fe, la UNL fue el centro de socialización política para muchos estudiantes deseosos de 
participación. Es en ese contexto histórico que puede rastrearse el origen del grupo de los radicales universitarios. De acuerdo con Karl Manheim (1993), hay un aspecto generacional a tener en cuenta: la mitad de sus integrantes más destacados nacieron en la década de 1960 y para 1983 estaban terminando el colegio secundario o iniciando sus estudios universitarios. En consecuencia, fueron descubriendo su vocación por la participación política y, en distintos momentos de la década de 1980, se fueron inclinando por la participación activa en el movimiento estudiantil.

Un ex secretario municipal, al quien Ilamaremos Horacio, recuerda estos momentos en que la socialización política se vinculaba con la militancia secundaria y universitaria: «En el 83 yo estaba en cuarto año. En el auge democrático gana Alfonsín. Vengo de una familia radical, mi hermano mayor ya estaba en la universidad con la apertura de los centros. Las universidades se normalizaban, formé parte de toda esa primavera democrática del '83» (comunicación personal, 5 y 19 de abril, 2016). Como esta historia, otros integrantes del grupo tuvieron una militancia activa en los primeros centros de estudiantes.

El predominio de la UNL como espacio de participación estudiantil estuvo en sintonía con la histórica relación entre militancia política y universidad en Argentina (Mellado, 2015); además, se debió, por supuesto, a que la gran mayoría de quienes formaron parte del origen del grupo estudió en sus facultades. De los veintitrés entrevistados, dieciocho transitaron por diversas carreras de la UNL y dieciséis militaron en alguna agrupación política. Es decir que el paso por la universidad no solo les permitió formarse profesionalmente, sino que fue un ámbito de sociabilidad política fundamental para dos tercios de los entrevistados. Esto permite intuir el peso que tuvo este ámbito estudiantil en la construcción de vínculos interpersonales y de redes para muchos miembros del grupo (Granovetter, 1973), y también permite observar que no cubre a la totalidad del universo en cuestión, como se verá más adelante.

La Franja Morada, la agrupación universitaria ligada a la Unión Cívica Radical (UCR) (Beltrán, 2013), fue la que nucleó a estos jóvenes radicales en sus pasos por la militancia universitaria. Con la excepción de pocos casos, algunos de más edad que habían militado en el Movimiento Universitario Reforma Auténtica (MURA) u otros que lo hicieron en pequeñas agrupaciones 
independientes, la mayoría se inclinó por la tradicional rama universitaria del radicalismo. De los dieciséis entrevistados que militaron en una agrupación, trece lo hicieron en la Franja. Esta militancia, en sus casos, constituyó un espacio central de su vida cotidiana. A partir de ella se socializaron en el oficio político, pero también construyeron sólidos vínculos de amistad, en algunos casos de pareja. La intensidad con la que vivían el compromiso puede derivarse de que, en la mayoría de los casos, el involucramiento los llevó a acceder a cargos estudiantiles. En efecto, de estos dieciséis, trece accedieron a ellos. Es en este marco que puede rastrearse el origen del grupo de los «radicales universitarios», nucleados en torno a algunos jóvenes que ocuparon cargos estudiantiles en la década de 1980. Al calor del liderazgo de estos jóvenes, en las distintas facultades se tejieron relaciones que fueron conformando un grupo.

Claro que la creación de este grupo no fue un fenómeno novedoso para el radicalismo universitario; por el contrario, siguió una tradición con antecedentes en la Junta Coordinadora Nacional, que tuvo su epicentro en esta provincia y en esta ciudad (Altamirano, 1987). No es la novedad lo que interesa señalar aquí, sino cómo cierta actividad social —la militancia-, cierta identidad partidaria —el radicalismo- y cierto contexto histórico [270] - la primavera alfonsinista - constituyeron las condiciones propicias para fomentar nuevas formas de sociabilidad que derivarían en la construcción de una empresa colectiva en la que se embarcaron jóvenes que, justamente, querían «renovar» los grupos universitarios del radicalismo en Santa Fe.

La presencia creciente en cargos estudiantiles constituyó un primer paso en el camino de afianzamiento de lazos, determinación de objetivos comunes y creación de liderazgos (Blondel, 1987). Junto a este —como se verá en el próximo apartado-, la gestión universitaria permitió reforzarlos y ampliarlos. El pasaje de los cargos estudiantiles a los cargos de gestión universitaria ha sido la carrera más frecuente en este grupo. De los dieciséis individuos que militaron y tuvieron cargos estudiantiles, doce han ocupado luego cargos de gestión universitaria, pero cuatro han transitado por otros derroteros personales. Este es el caso de uno de los referentes del grupo, al que denominaremos Fernando, que pasó directamente de la política estudiantil a ocupar cargos políticos en el Concejo Deliberante de Santa Fe. Primero fue un «soldado», según sus palabras, trabajando de asesor cuando tenía solo 26 años, luego fue electo como concejal. 


\section{La gestión universitaria}

Uno de los principales referentes del «radicalismo universitario» es Mario Barletta, ${ }^{1}$ intendente de Santa Fe entre 2007 y 2011. Su trayectoria es distinta de la de los «jóvenes» descritos en el apartado anterior. Es uno de los «hermanos mayores», como lo presentó un miembro del grupo, ya que nació en 1953 y para la recuperación democrática ya tenía treinta años. Su participación estudiantil, por lo tanto, se inició en el periodo previo a la dictadura de 1976 dentro del MURA, una agrupación radical que luego fue parte de Franja Morada. Su trayectoria no incluyó, como en otros casos, cargos estudiantiles, tampoco un involucramiento temprano en la política partidaria, pese a su simpatía por el radicalismo, no participó de ninguna seccional radical ni tuvo cargos partidarios, y se afilió a la UCR de adulto, ya en el proceso de su candidatura a intendente.

Cuando Raúl Alfonsín asumió la presidencia en diciembre de 1983 Barletta era un joven ingeniero que había participado en proyectos importantes. Con la reapertura de las universidades, el rector normalizador, Benjamín Stubrin, le ofreció el cargo de decano normalizador de la Facultad de Ingeniería y Ciencias Hídricas (FICH) de la UNL. Inició así, con solo 29 años, una trayectoria en la gestión universitaria casi ininterrumpida, salvo por un breve periodo en la actividad privada hasta su asunción como intendente de Santa Fe en 2007, que incluyó los cargos de secretario de Ciencia y Técnica, secretario general y rector. La trayectoria de Barletta es solo una muestra de la importancia que tuvo la gestión universitaria en la consolidación de vínculos y la construcción del grupo. En efecto, los «radicales universitarios» fueron articulándose a partir de las gestiones de Juan Carlos Hidago (1986-1994), Hugo Storero (1994-2000) y el propio Barletta (2000-2007). La generación de los «hermanos mayores» incluía a Barletta y a otros funcionarios universitarios, como Storero y Julio Schneider.

Fue durante la segunda mitad de la década de 1980 y en los primeros años de la de 1990 que los jóvenes militantes de la Franja Morada, a los que ya se hizo referencia, comenzaron a ganar cargos en la Mesa Nacional de la agrupación y también a ocupar compromisos en los órganos universitarios

\footnotetext{
${ }^{1}$ Hemos decidido presentar los nombres reales en los casos en los que se presentan datos públicos de los miembros del grupo analizado y modificarlos en los casos en los que se citan extractos de las entrevistas realizadas para garantizar el anonimato.
} 
como consejeros estudiantiles. El grupo comenzó a afianzarse a partir de algunos objetivos comunes, destinado a ganar ciertos espacios institucionales, por ejemplo, uno de sus principales referentes había estado dos años en Buenos Aires, en la Mesa Nacional de Franja Morada, pero regresó para pelear por un lugar como consejero estudiantil. La reglamentación exigía haber aprobado más de la mitad de las materias y como él estaba más cerca de su espacio tuvo que «meter» quince materias en poco tiempo. Su «tarea militante», como afirma, era «estudiar». Finalmente, logró un lugar en el Concejo.

Eran años en los que el movimiento estudiantil se opuso a la reforma universitaria promovida por el presidente Carlos Menem, que finalmente se plasmó en la Ley de Educación Superior aprobada en 1995. En ese contexto, varios de estos jóvenes radicales promovieron un proyecto de «auto evaluación» universitaria como forma de contrarrestar la evaluación que proponía la ley. Uno de sus referentes, Alejandro Boscarol, logró imponer el proyecto como consejero superior y de este modo afianzó la relación con el rector Storero. Así, otra de sus figuras, José Corral, comenzó a trabajar en una oficina de la universidad que se denominó Unidad de Apoyo al Planeamiento y a la Evaluación, poco después fue nombrado secretario de Extensión Universitaria. Es a mediados de la década de 1990 que se encontraron los «hermanos mayores» con los «jóvenes». Si bien Corrral ya conocía a Storero y a Barletta, no tenían un vínculo establecido, pero desde entonces se convirtió, junto con otros miembros del grupo, en parte del equipo más cercano de colaboradores y funcionarios universitarios de Barletta.

Al reflexionar sobre este encuentro, uno de sus principales referentes del grupo recuerda que ya por entonces conformaban un colectivo que tenía una «vocación política», un «planteo de universidad» y «sabíamos a dónde queríamos ir». Se produjo así un encuentro que marcó una etapa de consolidación grupal, orientada a la gestión universitaria. De este modo, puede pensarse la primera articulación entre individuos con orígenes diversos. No todos quienes participaron activamente en la militancia universitaria, ni todos quienes ocuparon cargos de gestión en los primeros años posteriores a la recuperación democrática terminaron en el grupo de los «radicales universitarios». Se observa así la primera intersección entre dos espacios, en la que los individuos caracterizados por su «multiposicionalidad» (Boltanski, 1973) son los que terminaron formando parte central del grupo político. 
La gestión universitaria fue el espacio en el que el grupo se consolidó y se amplió. De los veintitrés entrevistados que forman parte del grupo y que ocuparon un cargo ejecutivo o legislativo en la Ciudad de Santa Fe entre 2007 y 2015, catorce tuvieron un paso previo por la gestión universitaria. No todos lo hicieron en cargos jerárquicos, pero sí en una carrera lo suficientemente larga como para consolidar lazos profesionales y, en no pocos casos personales, con los referentes o líderes del grupo. En suma, si el grupo se creó en torno a los espacios y a las prácticas de la sociabilidad de la militancia universitaria, su consolidación se debió, en buena medida, a la incorporación de nuevos lazos e intercambios, propios de la gestión de la educación superior.

La gestión universitaria fue el espacio que les permitió a varios miembros del grupo afianzar un perfil profesional y convertirse en «expertos» en determinadas áreas. Fueron numerosos los casos en los que los nombramientos en la Municipalidad respondieron a una lógica de continuidad de la gestión universitaria. Muchas áreas de gobierno fueron cubiertas por individuos que tenían a su cargo temáticas similares, aunque con un alcance y una lógica distintas. Esto ocurrió, por ejemplo, en las secretarías de Comunicación, Hacienda, Cultura o Desarrollo Social. Como se señaló antes, nueve de los veintitrés entrevistados que pueden considerarse parte importante del grupo, ya que han accedido a cargos de concejales o secretarios municipales, no pasaron por la gestión universitaria. Muchos de ellos, como se verá a continuación, tienen una trayectoria que mezcla lazos personales con participación política partidaria.

\section{El partido}

Otro miembro del grupo de los radicales universitarios entrevistados, al que nombraremos Roberto, pasó su juventud en los años de la recuperación democrática y despertó a la militancia a partir de sentirse cautivado por la figura de Alfonsín, una sensación que le transmitió su padre cuando solo tenía 14 o 15 años. Con esa edad comenzó a participar del centro de estudiantes de su colegio secundario, años más tarde inició sus estudios superiores. A diferencia de otros de sus compañeros del grupo político, no tuvo un paso por la militancia universitaria, no se formó en la UNL; cursó sus estudios en la Universidad Nacional de Entre Ríos (UNER), en la vecina ciudad de Paraná, pero no participó de la política estudiantil: «A la Facultad iba a estudiar. Estaba la Franja Morada y todo pero iba a estudiar. Militaba en Santa Fe en la Juventud Radical», recuerda; «Empezamos acá en este barrio, 
que es la seccional sexta, barrio Roma, del partido radical] y de ahí empecé mi caminito de hormiga que fui uno a uno cumpliendo todo el estamento del ABC político partidario» (comunicación personal, 8 de abril, 2017). A los veinticuatro años llegó a ser presidente de la Juventud Radical de su seccional y a los treinta presidente de la Juventud Radical del Departamento de la Capital. Inició así un camino de continuos cargos partidarios, no solo en la rama juvenil, casi en paralelo comenzó una carrera ininterrumpida de cargos políticos, que incluyeron los de asesor de concejal, secretario de bloque de concejales, concejal, cargos ejecutivos municipales y provinciales. Al describir su trayectoria, señala la importancia que tuvo una figura a la que reconoce como su «jefe político» de su «grupo interno», porque «el radicalismo tiene muchos grupos internos». Fue él, electo concejal, quien lo convocó como asesor y le abrió así un camino posterior.

La trayectoria de este entrevistado es una muestra de que el pasaje por la militancia y la gestión universitaria, si bien ha tenido una relevancia indudable para la construcción y la consolidación del grupo, que no casualmente se denomina de «radicales universitarios», no ha sido una condición excluyente. Esto se debe a que algunos de los «jefes» $\mathrm{o}$ «referentes» del grupo articularon su paso por la política universitaria con la inserción en las estructuras partidarias [274] de la UCR.

De este modo, algunos de referentes del grupo, como Darío Boscarol o Julio Schneider, participaron en paralelo en el ámbito universitario como partidario y fueron los primeros del grupo en lograr un cargo público al ser electos concejales en 1993 y 1999, respectivamente. Esta implantación múltiple los ubicaba en un lugar de nexo entre espacios diversos. Así como permitió, por un lado, la incorporación de militantes partidarios que no formaban parte de las agrupaciones universitarias, como el caso mencionado más arriba, por el otro, fortaleció la posibilidad de un mayor vínculo con las autoridades universitarias. El propio Barletta no tuvo ningún cargo partidario, ni participó activamente en el radicalismo, pero dado su rol institucional en la universidad los dos concejales radicales electos que salieron de la UNL — ya mencionados — los llamaban para armar reuniones de trabajo y discusión política.

Esta descripción permite ubicar la participación en las estructuras formales del partido en su justa medida. Es claro que no se trataba de un grupo de militantes «independientes»: su vínculo con el radicalismo no era 
solo de simpatía, sino que sus referentes más encumbrados participaron de las estructuras partidarias desde muy jóvenes. No fueron, sin embargo, parte del grupo que dominó al radicalismo santafesino en los últimos años de la década de 1990 y los primeros años del siglo xx. La relación con la universidad, en efecto, no era valorada por parte de la dirigencia partidaria de la ciudad que privilegiaba una militancia barrial, mediada por las estructuras partidarias y no por la universidad. Este «radicalismo barrial», tal como es conocido en Santa $\mathrm{Fe}$, es una facción partidaria contraria a la de los «universitarios» que cuenta con sus propios liderazgos y candidaturas.

La primacía del radicalismo universitario se alcanzó a partir de la elección de Mario Barletta como intendente municipal. Hasta entonces, habían ubicado a algunos concejales en el Concejo Deliberante de Santa Fe y logrado imponer la candidatura a intendente del rector Hugo Storero en 1999, pero sin ganar las elecciones, las cuales quedaron en manos del PJ. En este sentido - como se observó en los apartados anteriores-, el grupo fue creciendo, fundamentalmente, de la mano de la gestión universitaria, pero sin dejar de participar activamente en las luchas internas del radicalismo.

La socialización partidaria y la participación activa en los órganos de la UCR ha sido una constante para buena parte de los miembros del grupo. Casi la totalidad de los entrevistados confirmaron estar afiliados a la UCR, es decir que quienes forman parte del grupo político son hombres y mujeres no solo simpatizantes, sino formalmente vinculados al partido. En algunos casos, se trata de un vínculo de muchos años que se remonta a la adolescencia o a la juventud, en otros, a una relación más cercana en el tiempo, ligada a un gesto destinado a mostrar el involucramiento en el proyecto político del grupo.

Visto desde el partido político, es evidente que la universidad es uno de los entornos partidistas del radicalismo santafesino; sin embargo, si el enfoque se corre del partido hacia el grupo como espacio de sociabilidad y construcción política, se observa que no es posible reducir al segundo como un simple entorno del primero. Por un lado, porque no todos los miembros del grupo formaron parte activamente de las dinámicas partidarias, por el otro, porque su conformación se originó en torno a las dinámicas universitarias, tanto estudiantiles como de gestión. En este sentido, la historia del grupo está marcada por una construcción dentro del campo universitario, aun cuando algunos de sus referentes eran activos participantes del radicalismo. 
La incorporación de algunas figuras centrales como Storero o Barletta, pero también varios de los secretarios universitarios que este último nombró en su gestión, los cuales no provenían de la política partidaria, solo puede comprenderse por la autonomía relativa de lo universitario respecto de lo partidario.

Si bien nunca tuvo una total autonomía respecto del espacio del radicalismo santafesino, la consolidación grupal se asoció, según muchos de sus participantes, a la experiencia de gestión universitaria que los llevó luego a decidir dar la pelea por el gobierno de la ciudad. Ese salto, sin embargo, fue posible gracias a la intermediación entre ambos campos, el universitario y el partidario, por aquellos que, si bien eran más jóvenes que las autoridades universitarias, tenían una larga experiencia en las «batallas» internas del radicalismo. Como recuerda uno de los principales referentes del grupo, al que se llamará Jaime, Storero «había sido presidente del Colegio de Arquitectos, venía, digamos, de un tipo muy activo en la sociedad civil, pero no tanto en la política partidaria». Y lo mismo ocurría con Barletta:

Nosotros teníamos quince años menos, pero teníamos muchos campeonatos más encima que él que se asomaba a la vida política, digamos. Incluso, cuando fue candidato a intendente, nosotros teníamos en el lomo muchas elecciones internas, generales y qué se yo [...]. Ni Hugo ni Mario habían tenido esa experiencia política que sí habíamos tenido nosotros, ellos habían tenido una vida más universitaria, digamos (comunicación personal, 14 de mayo, 2018).

La «movilización» (Chazel, 1975) de estas figuras universitarias fue producto del empuje de quienes formaban parte del entramado partidario. En este sentido, puede hablarse de un «reclutamiento» en el sentido tradicional del término, asociado con el modo en que los partidos políticos seleccionan a sus candidatos de diversos medios sociales e institucionales. Pero en este caso la relación es más compleja, ya que no involucra solo el acceso a cargos dentro del campo político-partidario, sino relaciones que se establecen entre espacios diferentes. A modo de ejemplo, varios de los entrevistados han dicho que en el contexto de los primeros años de la recuperación democrática quien «convocó» a Barletta a la universidad fue Darío Boscarol, pero no para que ocupar un lugar "político», sino de gestión universitaria. Como ya se expuso, la figura de Barletta distaba de poder ser asociada a un afiliado con participación activa en los órganos partidarios del radicalismo. 


\section{La municipalidad}

Otro de los entrevistados, al que se llamará Germán, nació en un pueblo del centro de la provincia de Santa Fe en 1954. Al finalizar sus estudios secundarios se trasladó a Rosario para estudiar ingeniería civil. Se recibió a fines de la década de 1970 y desde entonces hasta 2007 se dedicó a ejercer su profesión en forma privada. Cuando asumió Barletta, lo nombró secretario de Obras Pública y Recursos Hídricos de la Municipalidad de Santa Fe, cargo que continuó ejerciendo en la intendencia de José Corral. De los entrevistados del grupo de los «radicales universitarios», es de los pocos que no tuvieron paso por la militancia universitaria, por la gestión universitaria o por la militancia partidaria. Más bien, sigue el perfil de quienes deciden, luego de una extensa actividad en la actividad privada, dar el salto a la función pública. Al contar este «salto», recuerda:

Barletta me ofreció el cargo y también evaluó mi currículum profesional y, bueno, me pareció bueno el desafío porque yo ya había trabajado mucho en mi actividad privada y me parecía bueno cambiar. Fundamentalmente, me parecía muy bueno por la calidad de persona que era en ese momento y es el exintendente Mario Barleta. Me pareció que estaba formando un gabinete muy serio y me pareció que estaba bueno dejar por algunos años la actividad privada y ejercer lo público para ver cómo era la actividad pública (comunicación personal, 4 de mayo, 2017).

Su elección para una secretaría muy sensible a los problemas de Santa Fe, como son las inundaciones (Beltramino, 2018), y en una temática muy identificada con la expertise del propio Barletta es una muestra de que la pertenencia al núcleo grupal y el pasaje por las distintas etapas e instituciones del cursus honorum de la política universitaria y partidaria no fue una condición excluyente para ocupar un cargo ejecutivo, una vez que el proyecto de «ganar la ciudad» se concretó.

Sin embargo, no puede dejar de mencionarse que se trató de casos excepcionales. En total, entre la gestión de Barletta y la primera de Corral fueron veinte individuos, trece varones y siete mujeres, quienes ocuparon los cargos más altos de la jerarquía ejecutiva municipal. Solo tres provenían, al momento de asumir, del sector privado, el resto dio el salto desde la universidad o de otros cargos públicos. Esto muestra el carácter político del 
grupo, que al acceder a gobernar la ciudad contaba con una extensa red de vínculos dentro de sus propios militantes para poder reclutar allí a la mayoría de sus funcionarios; pero también que estos tenían un perfil técnico como consecuencia del pasaje por la gestión universitaria. A diferencia de otras empresas político-electorales exitosas que llegan al poder sin una estructura técnica de apoyo, en este caso se trataba de un grupo ya consolidado que se propuso dar un salto desde la universidad a la ciudad.

En efecto, los relatos de quienes forman parte del grupo desde sus orígenes y son los principales referentes o líderes del espacio narran el pasaje entre la universidad y la municipalidad como producto de un proyecto para el cual desplegaron las estrategias que consideraron, dentro de las limitaciones propias de una reflexividad situada, más adecuadas en cada momento. El primer intento por ganar la intendencia, infructuoso, fue en 1999, cuando ungieron como candidato radical de su sector al rector Storero, en unas elecciones que todavía se regían por la Ley de lemas. ${ }^{2}$ El grupo repitió el intento en 2003, también con resultado esquivo. ${ }^{3}$ Sin embargo, pese a las derrotas, las elecciones fueron la posibilidad de mantener representación en el Concejo Deliberante, algo que el grupo ya había logrado con la elección de Darío Boscarol como concejal, en tres periodos consecutivos desde 1993 a 2005. En efecto, desde 1999, en todas las elecciones del periodo considerado en este artículo, el grupo logró acceder a por lo menos una banca en el Concejo Deliberante. ${ }^{4}$

La candidatura de Barletta de 2007, en este sentido, puede ser considerada como el resultado de un proceso iniciado varios años antes. Hay factores políticos e institucionales que hicieron a esas elecciones propicias para el triunfo, como la eliminación de la Ley de lemas (Rulli y Centeno,

\footnotetext{
${ }^{2}$ La Ley de Lemas consistía en la posibilidad de que cada partido o «lema» presentara varios candidatos para un mismo cargo. La victoria quedaba en manos del candidato más votado del lema ganador. En la elección de 1999, Hugo Storero obtuvo 55267 votos y fue el más votado de su lema; sin embargo, perdió la elección frente al candidato peronista Marcelo Álvarez que obtuvo 82423 votos, de un lema que alcanzó 107537 votos. Sobre las implicancias de esta modalidad electoral en Santa Fe, véase Silvia Robin (1994).

${ }^{3}$ En esa elección resultó ganador Martín Balbarrey que obtuvo 36240 votos, de un lema que alcanzó 89043 votos. Storero volvió a ser vencedor de su lema, con 24986 votos, de un total de 56560.

${ }^{4}$ En 1999 y 2003 fue electo Julio Schneider, en 2001 Alejandro Boscarol, en 2005 Carlos Pereira, en 2007 Adriana Molina, en 2009 José Corral, en 2011 Ariel Rodríguez y en 2013 Adriana Molina y Mariano Cejas.
} 
2006) o los recuerdos cercanos de las inundaciones en la ciudad en 2003 y 2007 (Beltramino, 2018). Estos temas, sin embargo, exceden los alcances de este artículo. Es de interés señalar, en cambio, el rol desempeñado por la estrategia grupal. Uno de los principales referentes, al quien se referirá como Jaime, recuerda que en 2007 el candidato del Frente Progresista Cívico y Social (FPCyS), Hermes Binner, quería contar con Barletta como su candidato a vicegobernador. El escenario era auspicioso, ya que las encuestas mostraban que tenía una gran posibilidad de ganar, como finalmente sucedió: Binner fue electo gobernador con 48,6\% de los votos. Algunos del grupo pensaban que «tenían que agarrar» porque era algo «seguro»; otros, entre los que estaban los principales referentes, creían que no porque el «objetivo del grupo político era la ciudad», porque, como también expresa Jaime, «es poder político real, digamos. La Vicegobernación es como que vos acompañas el proyecto político de otro, pero como que el grupo logra crecer ganando la ciudad. Ya teníamos concejales».

En 2006 Barletta no se imaginaba ser intendente, ya que estaba transitando su gestión como rector. Fue el grupo de «jóvenes» quienes acudieron a su oficina con la propuesta de su candidatura. La idea, al principio, no pareció atraer al rector, que por esos días estaba preparando un viaje a Francia por cuestiones de gestión universitaria. Sin embargo, en poco tiempo, la idea no le pareció tan descabellada. Luego de volver a su casa, tomó el teléfono y les dijo: «vénganse a casa».

\section{Conclusión: el grupo como objeto de análisis de los procesos políticos urbanos}

El estudio del grupo de los radicales universitarios tiene ciertas particularidades, propias de la realidad local de la ciudad de Santa Fe; sin embargo, el análisis empírico puede ser útil a la hora de emprender otras investigaciones similares, a partir de seis puntos a tener en cuenta:

En primer lugar, las identidades y tradiciones políticas. Las referencias a las identidades políticas constituyen una amalgama que permite cierto reconocimiento por parte de un conjunto de individuos. En el caso abordado, el radicalismo no solo es un partido político, sino una referencia que para muchos de los entrevistados se asocia con aspectos ligados con las historias familiares, las vivencias cotidianas de su niñez o adolescencia, sus relaciones de amistad, entre otros. En este sentido, constituye una identidad política 
que, más allá de una definición ideológica, es parte de un espacio de reconocimiento mutuo, que potencia el vínculo con el otro. A diferencia de lo que ocurrió en algunas ciudades del país, como en Buenos Aires, donde el radicalismo fue perdiendo peso en los últimos años del siglo xx y los primeros del xxI (Obradovich, 2016), en Santa Fe el radicalismo se mantuvo como una tradición presente en una parte significativa de sus clases medias, al igual que en otras ciudades del país. Este peso es el resultado de un proceso sociohistórico, tanto en el ámbito político como en el socio-urbano. Es por ello que, como muestran las entrevistas, el análisis de estas tradiciones permite comprender la relación que vincula al individuo con el grupo, pero también al presente con el pasado.

En segundo lugar, las generaciones. Estas pueden ser definidas de dos maneras: una ligada a la edad biológica, otra a la política. En el primer caso, asociada con el momento de nacimiento, en el segundo, con el de ingreso a la actividad política, frecuentemente a través de la militancia. En el caso aquí analizado, se expresan ambas dimensiones: se trata de un conjunto de individuos que, en su mayoría, nacieron en fechas cercanas e ingresaron a la política en el mismo contexto histórico. Eso favoreció el desarrollo de vínculos interpersonales, indispensables a la hora de conformar un grupo; sin embargo, no fue óbice de establecer vínculos con los «hermanos mayores». En ese sentido, el análisis del modo en que se crean esos vínculos intra e intergeneracionales es otro punto que coadyuva a la comprensión del modo en que se constituye y refuerza el grupo político.

En tercer lugar, las movilizaciones. La existencia de determinadas tradiciones políticas en miembros de una misma generación puede dar lugar al encuentro de individuos bajo determinadas condiciones sociopolíticas. En el caso analizado, la «primavera democrática» en general y la figura de Raúl Alfonsín en particular, parece haber sido un imán que movilizó a muchos jóvenes de entonces y que los condujo a nuclearse en torno a un proyecto grupal común. En este sentido, el grupo de los radicales universitarios es tributario de la generación alfonsinista y esto le dio cierto sentido de unidad e identificación común, aun cuando, como observó, no es excluyente.

En cuarto lugar, las instituciones. Una de las virtudes de centrar el análisis de los grupos es que las instituciones son observadas en la medida - y solo en la medida - que desempeñan un rol en la creación de lazos colectivos, es decir, sin presuponer una importancia que quizá no tengan. 
No todos los grupos políticos se consolidan transitando por las mismas instituciones, estas son, en muchos casos, espacios que permiten el desarrollo de proyectos grupales. En el caso analizado se observa que la universidad, el partido y la municipalidad han constituido las instituciones más significativas. La trayectoria del grupo puede leerse como una estrategia de posicionamiento en todas ellas y la búsqueda por ganar espacios que les permita pasar de una a otra, pero también se observa que tienen cierta autonomía relativa, ya que no todos sus miembros han tenido una participación activa en todas.

En quinto lugar, las redes. Las relaciones de los individuos que forman parte del grupo se establecen a partir de una red de vínculos que, si bien transitan por los espacios institucionales, los desbordan ampliamente. Las relaciones familiares, de amistad, de vínculo profesional e incluso de vecindad, máxime en una ciudad media como Santa Fe, refuerzan las relaciones y crean vínculos sólidos. De acuerdo con los entrevistados, con el correr de los años los vínculos políticos se funden con las relaciones afectivas. En este sentido, la creación del grupo no puede disociarse del análisis de las formas de sociabilidad que entrelazan a una red de vínculos personales y permiten crear la idea de un «nosotros» que se opone a un «otro».

En sexto lugar, los liderazgos, un rol fundamental en la política. La mayoría de quienes participan activamente en la vida política reconocen con frecuencia referentes o «padrinos», a través de quienes entraron en política y en relación con quienes se construyen lazos de lealtad. Si bien estos liderazgos no son fijos, constituyen por lo general el nodo sobre el cual se despliega una serie de relaciones secundarias. El caso estudiado en estas páginas muestra esto. El grupo se conformó sobre la base de pocos referentes políticos de la vida estudiantil universitaria que entablaron vínculos con algunas autoridades universitarias. Así se constituyó un «núcleo» complementado por individuos que fueron acercándose y ocupando diversos lugares en el entramado de relaciones grupales.

En síntesis, las tradiciones, generaciones, movilizaciones, instituciones, redes y liderazgos permiten realizar una génesis de la conformación y consolidación de los grupos políticos, contribuyendo a comprender el modo en que la sociabilidad política se despliega en diversos contextos sociourbanos. 


\section{Referencias bibliográficas}

1. Aboy Carlés, Gerardo. (2001). Las dos fronteras de la democracia argentina. La reformulación de las identidades políticas de Alfonsín a Menem. Rosario: Homo Sapiens.

2. Agulhon, Maurice (2009). El círculo burgués. La sociabilidad en Francia. 18101848. Buenos Aires: Siglo xxı.

3. Altamirano, Carlos. (1987). La Coordinadora: elementos para una interpretación. En: Nun, José y Portantiero, Juan Carlos (comps.). Ensayos sobre la transición democrática en la Argentina (pp. 295-332). Buenos Aires: Puntosur.

4. Annunziata, Rocío. (2016). Representación, deliberación y escala: cambiar el enfoque sobre lo local en la participación. En: Mauro, Sebastián; Ortiz de Rozas, Victoria y Paratz Vaca Narvaja, Martín (comps.). Política subnacional en Argentina. Enfoques y problemas. Buenos Aires (pp. 315-334). Buenos Aires: CEAP-UBA.

5. Auyero, Javier. (2001). La política de los pobres. Las prácticas clientelísticas del peronismo. Buenos Aires: Manantial.

6. Beccaria, Luis; Feldman, Silvio; González Bombal, Inés; Kessler, Gabriel; Murmis, Miguel y Svampa, Maristella. (2002). Sociedad y sociabilidad en la Argentina de los 90. Los Polvorines: UNGS.

7. Beltramino, Tamara. (2018). Riesgos colectivos, debate público y respuestas institucionales a las inundaciones en la ciudad de Santa Fe (Santa Fe) entre 2003 y

[282] 2011. Quid, 16 (8), pp. 230-234.

8. Beltrán, Mónica. (2013). La Franja, de la experiencia universitaria al desafío del poder. Buenos Aires: Aguilar.

9. Blondel, Jean. (1987). Political Leadership: Towards a General Analysis. London: SAGE.

10. Boltanski, Luc. (1973). L'espace positionnel: multiplicité des positions institutionnelles et habitus de clase. Revue de Sociologie Française, 14 (1), pp. 3-26. https://doi.org/10.2307/3320321

11. Bourdieu, Pierre (1986). L'illusion biographique. Actes de la Recherche en Sciences Sociales, 62-63, pp. 69-72. https://doi.org/10.3406/arss.1986.2317

12. Briquet, Jean-Louis, (1994). Communiquer en actes. Prescriptions de rôle et exercice quotidien du métier politique. Politix. 7 (28), pp. 16-26. https://doi. org/10.3406/polix.1994.1879

13. Briquet, Jean-Louis et Sawicki, Frederic. (1989). L'analyse localisée du politique. Politix. 7, pp. 6-16. https://doi.org/10.3406/polix.1989.1392

14. Chazel François. (1975). La mobilisation politique: problèmes et dimensions. Revue Française de Science Politique. 25 (3), pp. 502-516. https://doi.org/10.3406/ rfsp.1975.393616

15. Dahl, Robert. (1961). Who Governs? Democracy and Power in an American City. New Haven: Yale University. 
Sociabilidad política y grupos políticos. El radicalismo universitario en la Ciudad de Santa Fe...

16. Dubar, Claude (1998). Trajectoires sociales et formes identitaires: clarifications conceptuelles et methodologiques. Sociétés Contemporaines, 29, pp. 73-85. https:// doi.org/10.3406/socco.1998.1842

17. Espejel Espinosa, Alberto. (2013). El estado de la cuestión de los grupos al interior de los partidos. Entre facciones, fracciones y tendencias. Revista Mexicana de Análisis Político y Administración Pública, ॥ (1), pp. 131-154.

18. Gaxie, Daniel. (1994). Le maire entre disciplines et libertés. Remarques sur les limites du travail politique. Politix, 28, pp. 140-148. https://doi.org/10.3406/ polix.1994.1888

18. González Bernaldo de Quirós, Pilar (2001). Civilidad y política en los orígenes de la Nación argentina. Las sociabilidades en Buenos Aires, 1829-1862. Buenos Aires: FCE.

20. González Bernaldo de Quirós, Pilar. (2008). La «sociabilidad» y la historia política. Nuevo Mundo Mundos Nuevos. Recuperado de http://journals.openedition. org/nuevomundo/24082

21. Granovetter, Mark. (1973). The Strength of Weak Ties. The American Journal of Sociology. 78 (6), pp. 1360-1380. https://doi.org/10.1086/225469

22. Gurvitch Georges. (1938). Las formas de la sociabilidad: ensayos de sociología. Buenos Aires: Losada.

23. Ihl, Olivier. (2002). Socialisation et événements politiques. Revue Française de Science Politique. 52 (2-3), pp. 125-144. https://doi.org/10.3406/rfsp.2002.403704

24. Lagroye, Jacques et Offerlé, Michel (comps.). (2010). Sociologie de l'institution. Paris: Belin.

25. Landau, Matías. (2008). Política y participación ciudadana en la Ciudad Autónoma de Buenos Aires. Buenos Aires: Miño y Dávila.

26. Losada, Leandro. (2008). La alta sociedad en la Buenos Aires de la Belle Époque. Buenos Aires: Siglo xxı.

27. Manheim, Karl. (1993). El problema de las generaciones. Revista Española de Investigación Sociológica, 62, pp. 193-242. https://doi.org/10.2307/40183643

28. Meccia, Ernesto (dir.). (2019). Biografías y sociedad. Métodos y perspectivas. Santa Fe: UNL.

29. Mellado, Virginia. (2015). Socialización y formación de las élites políticas argentinas: itinerarios universitarios y aprendizajes. Pro-Posições, 26 (2), p. 163-185. https://doi.org/10.1590/0103-7307201507707

30. Obradovich, Gabriel. (2016). La conversión de los fieles. La desvinculación electoral de las clases medias de la Unión Cívica Radical. Buenos Aires: Teseo.

31. Passeron, Jean-Claude. (1990). Biographies, flux, itinéraires, trajectoires. Revue Française de Sociologie, 31 (1), pp. 3-22. https://doi.org/10.2307/3321486

32. Robin, Silvia. (1994). Ley de lemas y dinámica del sistema de partidos en la provincia de Santa Fe. Estudios Sociales, 1 (6), pp. 85-95. https://doi.org/10.14409/ es.v6i1.2313 
33. Rulli, Mariana y Centeno Lappas, Federico. (2006). Procesos de reforma política: la derogación de la Ley de Lemas en Santa Fe. Temas y Debates, 10 (12), pp. 151-180.

34. Sautú, Ruth (comp.). (1999). El método biográfico. La reconstrucción de la sociedad a partir del testimonio de los actores. Buenos Aires: Editorial de Belgrano.

35. Sawicki, Fréderic. (2011). Para una sociología de los entornos y las redes partidistas. Revista de Sociología, 25, pp. 37-53. https://doi.org/10.5354/0719529X.2011.27497

36. Simmel, Georg. (2002). Cuestiones fundamentales de sociología. Barcelona: Gedisa.

37. Solís Delgadillo, Diego. (2017). Hacia una definición del concepto grupo de interés. Perfiles Latinoamericanos, 25 (50), pp. 83-101. https://doi.org/10.18504/ pl2550-005-2017

38. Vázquez, Melina; Vommaro, Pablo; Núñez, Pedro y Blanco, Rafael (comps.). (2017). Militancias juveniles en la Argentina democrática. Trayectorias, espacios y figuras de activismo. Buenos Aires: Imago Mundi. 